also point out that, without the furore over the leak, Samios would probably have offered to stay in place until a successor was found. Instead, he will step down at the end of next month.

Samios, who turned 65 last Friday, but looks and acts ten years younger, says that he did consider a resignation accepting blame for failing to find the leak earlier. But he rejected the idea, saying "It's not my style to quit, it's not true, and it wouldn't have solved very much."

The crisis that has engulfed Brookhaven since the leak was found has led Samios to reflect more widely on the public's understanding of science. "There's an anti-science mood in the world today," he says. "You see it all over; there is a distrust of science. Look at how worried people are about cloning." This mood, he says, "is stronger than it was five years ago. Science in general has to make more cogent arguments than it has in the past. We haven't communicated the importance and value of our work."

Samios shares the blunt, engaging and energetic manner that characterizes so many successful sons of New York city. A brilliant physicist whose discovery of the Omega Minus particle in the $1960 \mathrm{~s}$ is considered by some colleagues to be worthy of a Nobel prize, he spurns intellectual aloofness and prides himself on being a man of action.

As chair of the American Physical Society's planning committee, for example Samios was a major behind-the-scenes force in the recent unified call by US scientific societies for more research funding (see Nature 384, 393; 1996).

Despite his deep involvement in science policy, Samios says he does not plan to work in Washington DC in the foreseeable future if he can help it. Having had little time for research in recent years, he says he is flattered to have already been invited to participate in scientific projects, but adds that it is "too early to comment" on what he might take up. Samios is supposed to complete a plan to clear up the tritium plume before he leaves. Running the laboratory has been "a wonderful responsibility", he says. "But not having that responsibility on my shoulders will be a great thing."

Brookhaven retains an interest in particle physics, and will be involved in the design of the Atlas detector for the Large Hadron Collider at CERN, the European Laboratory for Particle Physics in Switzerland. But its largest scientific interests now lie elsewhere. It needs a new director who can lead the laboratory beyond the Relativistic Heavy Ion Collider and into the next century.

In practice, this means a nuclear or condensed-matter physicist of exceptional political agility, ready and able to convince the people of Long Island that physics research can and must continue safely in their midst.

colin Macilwain

\title{
A window of opportunity is opened for Italian reforms
}

[ROME] Italy is giving its research agencies a unique opportunity to reform their notoriously bureaucratic management structures - the bane of scientists for decades - and to develop more effective ways of allocating research funds.

The Italian parliament agreed last week that the government should have the power to modify existing laws, without further parliamentary approval, where this is needed to promote efficiency in public institutions. As a result, Luigi Berlinguer, the research minister, now has the right to "reorder and rationalize all efforts related to the promotion and support of scientific and technological research".

The new law states that, in making changes to the activities of research agencies, consideration should be given to the need to increase the institutional flexibility of researchers and their ability to move between research institutes, universities and industry.

The so-called Bassanini law, named after its parliamentary sponsor, will take effect for just one year. Committees set up by major research organizations - including the national research council (CNR), the National Agency for New Technology, Energy and the Environment (ENEA), the Italian Space Agency (ASI) and the National Institute for Nuclear Physics (INFN) - as well as many smaller organizations and institutes, have four months in which to draw up proposed changes.

The ministry of research will then revise the proposals and present them to parliament for debate.

Any changes will have to be in line with the government's strategic goals for research. Last December, the government set up a toplevel committee of six ministers to develop a long-term research strategy based on clear priorities. These are being identified with the use of forecasting techniques and an analysis of Italy's research capacity and the needs of potential users of the research results.

A task force, headed by Giuseppe Tognon, under-secretary of state for research, is working with this committee to coordinate research and technology policies of the different ministries. "Previously, Italy's long-term plans have been no more than shopping lists, with little indication of priorities," says Alberto Silvani, a senior policy adviser to Berlinguer and a former researcher at the CNR Institute for Science Policy in Rome. Silvani says that the ministry wants to "concentrate, rather than scatter" its money, and plans to set up an assessment system to monitor the way in which research money is spent.

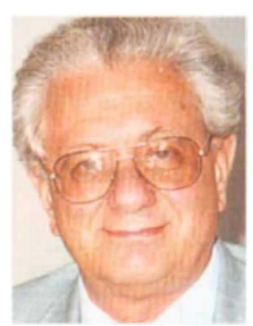

Berlinguer: powers to 'reorder' agencies lar it wants investigator-initiated research to be carried out exclusively in universities, which employ 60,000 professors, with the 3,000 researchers in CNR institutes carrying out strategic research.

There is also pressure from political and university quarters to remove the CNR's role in funding university research projects (see Nature 367, 398; 1994). Some have suggested that a new independent grant agency should be given this task, and that the CNR's central technology transfer support unit - which acts as a go-between for academics and industry - should be taken over by ENEA, which is Italy's principal applied research organization.

The Bassanini law will also permit reform of other research-related bodies such as the government's science and technology advisory committee (CNST). This was created by a 1989 law, but there have been no elections of representatives from the research community as no one has been able to define the electorate. Berlinguer would like the CNST to be restructured and to become fully active.

Luciano Maiani, the president of INFN - which is unlikely to face major changes says that the most helpful thing the Bassanini law could do would be to increase the mobility of researchers between institutes and universities. "We need to change the way people work, rather than hold large strategic discussions," he says.

This could involve further efforts to abandon the centralized competitions for university positions (concorsi). Many would welcome such a move (see Nature 378, 228; 1995), but it has had little support in parliament, which traditionally has a high number of professors.

With only 12 months to overhaul their entire management structure, tensions are already beginning to run high among research administrators. Maiani admits that they face a difficult task ahead. But, echoing a widely held sentiment, he says that the Bassanini law is a great chance for Italy, "and it would be a disaster if the opportunity were to be lost".

Alison Abbott 